\title{
Rethinking the Role of Resubsumption in Conceptual Change
}

\author{
Andrew Shtulman \\ Department of Psychology \\ Occidental College
}

\begin{abstract}
Why is conceptual change difficult yet possible? Ohlsson (2009/this issue) proposes that the answer can be found in the dynamics of resubsumption, or the process by which a domain of experience is resubsumed under an intuitive theory originally constructed to explain some other domain of experience. Here, it is argued that conceptual change is difficult in two distinct senses - that is, difficult to initiate and difficult to complete - and that Ohlsson's proposal addresses the latter but not the former. The implications of this argument for how conceptua change might be best facilitated in the science classroom are discussed as well.
\end{abstract}

In a classic study by McCloskey, Caramazza, and Green (1980), college undergraduates were asked to draw the trajectory of a ball shot through a curved tube resting on a flat surface. Although most participants had taken one or more physics courses prior to the study, many still drew physically impossible trajectories - that is, trajectories in which the ball continued to travel in a curved motion after exiting the tube. This intuition is inconsistent not only with the way objects actually move but also with the Newtonian principles these students had presumably learned in their prior coursework. From where do such misconceptions arise? Why do such misconceptions persist in the face of contrary experience and instruction? And how might such misconceptions be eliminated?

These are the questions at the heart of science education research, both in the physical sciences (Clement, 1982; Halloun \& Hestenes, 1985; Vosniadou \& Brewer, 1992) and the biological sciences (Au et al., 2008; Shtulman, 2006; Slaughter \& Lyons, 2003). They are also the questions at the heart of conceptual change research, or research on how knowledge is restructured at the level of individual concepts. Scholars of conceptual change have approached these questions from a variety of perspectives, including anomaly accumulation (Posner, Strike, Hewson, \& Gertzog, 1982), ontological reassignment (Chi, 2005), schema abstraction (Nersessian, 1992), and conceptual differentiation (Carey, 1991). Discontent with these approaches, Ohlsson (2009/this issue) has outlined a new approach to the study of conceptual change:

Correspondence should be addressed to Andrew Shtulman, Department of Psychology, Occidental College, 1600 Campus Road, Los Angeles, CA 90041. E-mail: shtulman@oxy.edu resubsumption. According to Ohlsson, conceptual change is best analyzed as the process by which a domain of experience, initially subsumed under one intuitive theory, is resubsumed under another. The process is initiated by "bisociation," or the creation of a two-to-one mapping between intuitive theories and domains of experience, and is completed by a competitive evaluation of the cognitive utility of each mapping.

Ohlsson's theory of conceptual change differs from previous theories in two important ways. First, it transforms the impetus of conceptual change from being about dissatisfaction with a single theory to being about differential satisfaction with two competing theories, thereby sidestepping what Ohlsson (2009/this issue) calls the "assimilation paradox" or the problem that "all information, including falsifying arguments and contradictory data, can in principle, be assimilated to a prior conception without any but the most minor and superficial accommodations" (p. 22). Second, it posits a mechanism of conceptual change that might operate at any level of abstraction and at any grain of knowledge, thereby eliminating the unparsimonious (and unprincipled) distinction between ontological shifts and other forms of knowledge restructuring (e.g., Chi, 2005).

Ohlsson's theory is an important contribution to the conceptual change literature in that it highlights aspects of conceptual change that have been either ignored or neglected by previous theories. That said, Ohlsson's theory suffers from the same limitation as previous theories in that it fails to provide a complete explanation of conceptual change. The problem, as I see it from a developmental perspective, is that Ohlsson attempts to answer the question of why conceptual change is difficult (yet possible) without engaging the truly difficult part of conceptual change - namely, the process of 
acquiring concepts/theories with different representational capacities than the concepts/theories one already possesses. In other words, what makes conceptual change difficult is not the task of evaluating two competing theories of the same phenomena but the task of constructing a new theory altogether.

Another way of framing the problem is that Ohlsson's theory addresses the question of why conceptual change is difficult to complete but does not address the question of why conceptual change is difficult to initiate. Below I discuss each question in turn, highlighting both the strengths and weaknesses of Ohlsson's approach. I then discuss the implications of this argument for how conceptual change may be facilitated in the science classroom, focusing mainly on the instructional implications that Ohlsson draws from his own theory. The examples I have chosen to support and illustrate my argument are drawn from the science education literature, as this literature provides some of the clearest examples of conceptual change (and some of the finest examples of conceptual change research). This choice of examples should not be taken to imply that my treatment of conceptual change applies only to scientific concepts or that my criticisms of Ohlsson apply only to conceptual change in science. Science just happens to provide particularly fertile grounds for studying conceptual change more generally (see Carey, 2000).

\section{WHY IS CONCEPTUAL CHANGE DIFFICULT TO INITIATE?}

The distinction between initiating conceptual change and completing conceptual change maps (roughly) onto the distinction between theory discovery and theory justification in the philosophy of science (Popper, 1956; Reichenbach, 1938). Theory discovery is the process of formulating (or learning) a genuinely novel theory - that is, a theory that appeals to different causal constructs than those appealed to by previous theories of the same phenomena. Theory justification, on the other hand, is the process of evaluating a preformulated theory, either through empirical investigation or inferential application. Although the two processes can, and do, overlap in contexts where the to-be-discovered theory is formulated over the same concepts as the to-be-rejected theory (see, e.g., Klahr \& Dunbar, 1988; Klahr, Fay, \& Dunbar, 1993), they do not overlap in contexts where the two theories are formulated over different concepts altogether (Carey, 1985, 1991).

This situation is well illustrated by research on children's early understanding of matter (Piaget \& Inhelder, 1974; Smith, Carey, \& Wiser, 1985; Smith, Maclin, Grosslight, \& Davis, 1997). By the time children receive formal instruction on the nature of matter, they have encountered numerous examples of material kinds (e.g., water, sand, wood, glue) and material processes (e.g., breaking, melting, dissolving, floating). These examples are interpreted on the basis of what
Smith et al. (1997) called "Commonsense Theory of Matter 1," according to which all matter is readily observable and all material objects are spatiotemporally discrete. Absent from this theory is any notion of the internal structure of matter, as demonstrated by young children's inability to compare objects on the basis of their density. For instance, when preschool and elementary-school-aged children are presented identically colored blocks of varying sizes (e.g., 1 cubic $\mathrm{cm}$ vs. 3 cubic $\mathrm{cm}$ ) and varying materials (e.g., steal vs. aluminum), they can easily sort them by size but not by material — a task that requires a size-to-weight comparison. Many children of this age also deny (a) that a large ball of wax could weigh less than a small ball of clay, (b) that a single grain of rice has any weight at all, (c) that air is composed of matter, and (d) that styrofoam will continue to exist if repeatedly divided in half. These findings, and others (e.g., Au, 1994; Nakhleh, Samarapungavan, \& Saglam, 2005), suggest that children's initial understanding of matter is fundamentally incompatible with a particulate theory of matter, let alone an atomic theory of matter.

The child's transition from a commonsense theory of matter to a (quasi-)scientific theory of matter is a prime example of conceptual change. Can this example be explained in terms of bisociation and resubsumption? I would argue that it cannot for the simple reason that children do not possess the concept density in any form suitable for participating in bisociation or resubsumption. The concept density must first be derived, discovered, or inferred, and Ohlsson describes no mechanism for doing so. The mechanisms of change that Ohlsson does describe are mechanisms that operate over concepts and theories already represented in an explicitly accessible format, albeit in another domain. Indeed, all the examples of "nonmonotonic change" that Ohlsson uses to illustrate his theory-for example, reconceptualizing politics as barter, reconceptualizing the economy as a feedback circle, reconceptualizing shoe pricing as the effect of trade globalization - presuppose the very concepts whose acquisition may need explaining. As a result, these examples are a far cry from what historians of science, like T. S. Kuhn (1962) and Kitcher (1993), or cognitive developmentalists, like Carey (1985) and Vosniadou (1994), would refer to as conceptual change.

What, then, would such scholars refer to as conceptual change? The answer lies in distinguishing conceptual change, or "strong knowledge restructuring," from belief revision, or "weak knowledge restructuring" (Vosniadou \& Brewer, 1987). Whereas both forms of knowledge restructuring involve changing one's beliefs, only the former involves changing the concepts over which those beliefs are formulated (Carey, 1991; Thagard, 1992). Put differently, belief revision results in a new set of propositional attitudes about what is and is not true, but conceptual change results in the ability to formulate propositional attitudes that were previously unformulable. Note that, on this view of knowledge restructuring, conceptual change differs from belief revision in kind, not 
degree. Descriptive labels like "strong" versus "weak" or "deep" versus "shallow" may thus be misleading, as they imply that belief revision and conceptual change are part of a continuum yielded by the same learning mechanism(s).

Ohlsson makes a concerted effort to distinguish between monotonic and nonmonotonic change, but he does not make any effort to distinguish between belief revision and conceptual change (two forms of nonmonotonic change). Indeed, he explicitly disavows such a distinction, arguing that "there never was any strong reason to believe that nonmonotonic changes come in exactly two magnitudes, weak and strong, and the resubsumption theory implies the more plausible view that they can vary in magnitude and impact" (2009/this issue, pp. 33).

I agree that distinguishing conceptual change from belief revision on the basis of magnitude (ontological vs. basic-level shifts; Chi \& Hausmann, 2003) or impact (global vs. local reorganization; T. S. Kuhn, 1977) is theoretically unsound, but I disagree that the distinction should be jettisoned altogether, for the reasons just articulated. To put a finer point on the matter, the problem with taking Ohlsson's stance is that it leaves no recourse for understanding instances of theory change in which the concepts of one's initial theory no longer play the same role - or any role - in one's final theory.

As an illustration, consider the difference between Ohlsson's examples of theory change and the examples drawn from the literature on children's understanding of matter. In Ohlsson's examples, concepts like feedback circle and trade globalization acquire new referents but do not acquire new meanings. In other words, they come to encompass a wider range of instances but do not come to embody a different set of properties. Concepts like weight and mass, on the other hand, acquire new referents and new meanings as children transition from a commonsense theory of matter to a quasi-scientific one. The young child's concept of weight, for instance, initially encompasses the meanings and referents of two scientifically distinct concepts: weight and density. Following conceptual change, this undifferentiated weight/density concept no longer plays a role in the child's theory of matter. Moreover, the newly acquired concept density could not have played a role in the process of bisociation because the child did not initially represent this concept as distinct from weight.

Obviously, a child who lacks the concept density must be able to acquire that concept via reference to his or her prior knowledge. At issue, then, is not the claim that conceptual change occurs independently of the concepts one already possesses but the claim that conceptual change involves the supplementation (or replacement) of preexisting concepts with genuinely novel ones. Prior to formal instruction, children simply do not possess a concept that plays the same referential and inferential roles that density plays in a scientific theory of matter. The same could be said for many other scientific concepts, including heat (Wiser \& Amin, 2001), inertia (McCloskey, 1983), gravity (Vosniadou \& Brewer,
1992), inheritance (Solomon, Johnson, Zaitchik, \& Carey, 1996), and natural selection (Shtulman, 2006).

If acquiring concepts like heat and inertia requires learning mechanisms other than bisociation and resubsumption, what might we make of Ohlsson's theory? I propose that Ohlsson's theory is best viewed as a theory of belief revision, as opposed to a theory of conceptual change (or both). In other words, Ohlsson's theory sheds light on why it is difficult to revise one's beliefs on the basis of an alternative concept/theory but does not shed light on why it is difficult to acquire a genuinely novel concept/theory. Given that concepts are the constituents of beliefs and that changing one's concepts will invariably change one's beliefs, Ohlsson's theory is not irrelevant to conceptual change; it just fails to address the most "mysterious" part of conceptual changethe part that some scholars have even branded as impossible (e.g., Fodor, 1981). Lest I leave the reader with an impression that accounting for the emergence of new representational resources is an intractable problem, I should point out that many promising solutions have already been proposed (see, e.g., Carey, 1999; Gentner \& Wolff, 2000; Nersessian, 2008; Tenenbaum, Griffiths, \& Niyogi, 2007; Zietsman \& Clement, 1997 ) but that discussing those solutions is beyond the scope of this commentary.

\section{WHY IS CONCEPTUAL CHANGE DIFFICULT TO COMPLETE?}

Conceptual change is slow. A full year of instruction rarely leads to complete understanding of a scientific theory, as demonstrated time and time again (e.g., Demastes, Settlage, \& Good, 1995; Halloun \& Hestenes, 1985). Although it is difficult to gauge the length of any one instance of conceptual change, research on numerical cognition has shown that children typically undergo a full year of counting before they understand the meanings of the words they are reciting (Le Corre, Van de Walle, Brannon, \& Carey, 2006; Wynn, 1990). Likewise, research on theory of mind has shown that children typically undergo a full year of desire-based reasoning before they begin reasoning about behavior on the basis of both beliefs and desires (Bartsch \& Wellman, 1995; Rakoczy, Warneken, \& Tomasello, 2007).

Why is conceptual change so difficult to complete once initiated? Ohlsson provides an answer to this question in the form of resubsumption. That is, he provides a full explication of the process by which experiences initially subsumed under one theory become subsumed under another, thereby emphasizing the fact that conceptual reinterpretations do not come for free. Rather, they come at the price of competitively (and continually) evaluating two mutually exclusive theories. As Ohlsson (2009/this issue) explains,

If a person finds himself or herself relying more and more often on theory $\mathrm{T}_{A+B}$ rather than on theory $\mathrm{T}_{B}$, and finds 
himself or herself being successful, then his or her confidence in $\mathrm{T}_{A+B}$ will gradually increase .... At some point, the difference in confidence levels reaches some threshold at which the person finds himself or herself believing the world is as theory $\mathrm{T}_{A+B}$ claims. (p. 30)

A prime example of competitive evaluation from the history of science is Darwin's discovery of evolution by natural selection (Gruber, 1974; Millman \& Smith, 1997). This process, chronicled by Darwin himself in the "Transmutation Notebooks," lasted more than a year and a half and involved the construction of multiple, extended analogies. Of primary importance to the issues at hand is that Darwin first realized "the final cause of [differential survival] must be to sort out proper structure and to adapt it to change" (as cited in Millman \& Smith, 1997, p. 170) 6 months before he outlined a complete sketch of his fledgling theory. In other words, Darwin's discovery of the concept of natural selection was followed by 6 months of applying that concept to beliefs he had acquired in the course of prior study. In fact, the above entry in Darwin's Transmutation Notebooks was followed not by a reflection on the potential importance of natural selection but by a passage on a seemingly unrelated topic: the sexual behavior of nonhuman primates (Gruber, 1974).

Just as Darwin took many months to unravel the implications of natural selection, students of evolution in today's science classrooms take many months to do the same. Recent research on evolutionary reasoning (e.g., Shtulman, 2006; Shtulman \& Calabi, 2008; Shtulman \& Schulz, 2008) has shown that most introductory biology students hold a naïve theory of evolution incompatible with natural selection. Rather than conceptualize evolution as the selective propagation of within-species variation, these students conceptualize evolution as the gradual (nongenetic) transformation of a species' underlying nature, or "essence," resulting in the uniform adaptation of all species members. Consequently, they interpret a wide range of evolutionary phenomenainheritance, adaptation, variation, domestication, speciation, extinction - in ways more similar to pre-Darwinian biologists than post-Darwinian ones (see Mayr, 1982, 2001).

One of the hallmarks of naïve evolutionary reasoning is the consistency with which it is exhibited across multiple tasks and multiple situations. That said, some students exhibit a form of "mixed reasoning" (Evans, 2008) or "synthetic reasoning" (Vosniadou, 1994) in which they demonstrate preDarwinian conceptions of some phenomena (e.g., speciation, extinction) and post-Darwinian conceptions of others (e.g., inheritance, adaptation). This pattern of reasoning is perhaps best understood in terms of resubsumption, where the individuals who exhibit such reasoning have acquired the basic concepts of Darwinian theory but have not yet reinterpreted all their beliefs about evolution in light of those concepts. Consequently, the misconceptions they formed outside the classroom, on the basis of an essentialist construal of biological kinds, continue to coexist with the accurate conceptions they acquired via formal instruction. This state of bisociation will presumably be resolved in favor of Darwinian theory through a process of competitive evaluation, such that phenomena once viewed "as an $A$ kind of thing" will come to be viewed "as a $B$ kind of thing instead" (Ohlsson, 2009/this issue, p. 31).

Enthusiasm for Ohlsson's framework aside, Ohlsson (2009/this issue) makes a claim about competitive evaluation that seems unnecessarily restrictive: "The manifest conflict between two mutually exclusive theories ... is not resolved, I suggest, by evaluating the strength of the relevant evidence but by estimating their relative cognitive utility" (p. 29). Ohlsson's preference for cognitive utility (or the ease with which a theory is utilized) over cognitive consistency (or the fit between a theory and the data it is intended to explain) is based on the assumption that intuitive theories are evaluated on different grounds than academic ones. Whereas academic theories are evaluated on the basis of their accuracy, intuitive theories are evaluated on the basis of their applicability to daily life.

I agree with Ohlsson that cognitive utility is a better measure of a theory's worth than cognitive consistency in so far that the former is inclusive of the latter. I disagree with Ohlsson, however, that cognitive consistency plays only a minor role in theory evaluation as practiced by nonacademics. Recent studies motivated by the theory-theory of cognitive development and the Bayesian theory of rational inference (e.g., Gopnik, Sobel, Schulz, \& Glymour, 2001; Kushnir \& Gopnik, 2005; Schulz \& Bonawitz, 2007; Schulz \& Gopnik, 2004; Sobel \& Kirkham, 2006; Sobel, Tenenbaum, \& Gopnik, 2004; Steyvers, Tenenbaum, Wagenmakers, \& Blum, 2003) have provided a wealth of evidence in favor of what Ohlsson (2009/this issue) describes as "the highly implausible hypothesis that lay people, students, and even little children ... continuously and spontaneously engage in the logically complex enterprise of relating theory to evidence" (p. 34). In other words, these studies have shown that individuals of all ages and academic aptitudes are sensitive to the information conveyed by different patterns of covariation and can use that information to generate causally relevant explanations, predictions, and interventions. Moreover, such findings have inspired (or were inspired by) computationally rigorous models of evidence-based causal inference (Gopnik et al., 2004; Jefferys \& Berger, 1992; Tenenbaum, Griffiths, \& Kemp, 2006).

Admittedly, the kind of evidence at issue in the aforementioned studies - observation and intervention - is not the kind of evidence at issue in science education. That kind of evidence is testimony, or the wholesale transmission of concepts, beliefs, and theories initially constructed by someone other than oneself (Harris \& Koenig, 2006). In Ohlsson's view, this distinction is important, as it changes the nature of the cognitive conflict preceding conceptual change from a theory-data conflict to a theory-theory conflict. "Does the sun orbit the Earth or vice versa?" asks Ohlsson (2009/this 
issue, p. 32). "Nobody has as yet traveled outside the solar system to see for themselves, so this is a matter of choosing between two conflicting theories of the [same data]" (p. 32).

The problem with separating theory-theory conflicts from theory-data conflicts, as Ohlsson attempts to do, is that the two are indistinguishable from the perspective of those undergoing conceptual change. A child who believes the earth is flat, for instance, would be as perplexed by the claim that gravity pulls objects toward the center of the earth (as opposed to its "bottom") as she would be by seeing a photograph of the earth taken from space. From this child's perspective, a counterintuitive theoretical claim is no different in kind from a counterintuitive observation; both are evidence that her intuitions are flawed.

At present, it is unclear whether, and how, Bayesian models of causal inference can integrate evidence derived from testimony with evidence derived from experience, yet dismissing the Bayesian approach altogether seems rather premature. Ohlsson's dismissal is particularly premature if his reason for doing so is the finding that most people are inept at explicitly coordinating data and theory (e.g., Klahr et al., 1993; D. Kuhn, Amsel, \& O’Laughlin, 1988; Koslowski, 1996). This finding is irrelevant to the Bayesian agenda, as proponents of this agenda (e.g., Gopnik \& Tenenbaum, 2007) explicitly deny that Bayesian inference requires conscious deliberation, just as Ohlsson (2009/this issue) denies that the process of competitive evaluation requires conscious deliberation (e.g., "The accumulation of information about cognitive utility is largely unconscious rather than deliberate"; p. 29). Indeed, Shultz's (2007) criticism that the Bayesian approaches to causal induction lack clarity regarding the relationship between implicit and explicit mechanisms of theory formation is applicable to Ohlsson's approach as well.

\section{HOW IS CONCEPTUAL CHANGE BEST FACILITATED?}

One's view of conceptual change inevitably shapes one's recommendations for how to facilitate conceptual change in the classroom. Ohlsson's (2009/this issue) view of conceptual change leads him to the recommendation that "students will do well if they acquire the target theory in some domain for which they do not already have a prior conception, and then are shown how to subsume the target domain under that theory" (p. 36). This recommendation has merit on the assumption that conceptual change begins with bisociation but has less merit on the assumption that conceptual change begins with the construction of new representational resources (which then begin the process of bisociation). In other words, if we view bisociation as the effect, not the cause, of conceptual change, then it is unclear why the target theory ought to be introduced in a domain other than the target domain itself. Presumably, the construction of new representational resources is difficult in any domain, let alone a domain whose constituent concepts and constituent beliefs are only weakly related to the target theory.

Theoretical considerations aside, there is much empirical evidence that conceptual change is readily facilitated within, rather than across, domains. Consider, for example, the teaching intervention designed by Smith et al. (1997) to facilitate conceptual change in children's early understanding of matter. Rather than introduce concepts like mass and density in a nonmaterial domain, Smith et al. introduced these concepts in the domain of matter itself. They did so by having students (a) weigh material objects they initially claimed to weigh nothing at all (e.g., one fleck of glitter, one dot of ink); (b) create schematic models of density in which units of mass were represented as "dots," units of volume were represented as "boxes," and density was represented as "dots per box"; (c) immerse objects of varying densities in liquids of varying densities to determine when and why objects float; and (d) weigh objects before and after their volume (but not their mass) had changed as a result of heating. These activities, in combination with much discussion and reflection on the properties of matter, yielded dramatic improvements in understanding, as measured by the kinds of tasks described above.

Smith et al.'s (1997) curriculum is not the only example of a within-domain instructional strategy that has proven effective at facilitating conceptual change. Other examples include Slaughter and Lyons's (2003) curriculum for teaching basic physiology; Hayes, Goodhew, Heit, and Gillan's (2003) curriculum for teaching basic cosmology; Vosniadou, Ioannides, Dimitrakopoulou, and Papademetriou's (2001) curriculum for teaching basic mechanics; Wiser and Amin's (2001) curriculum for teaching basic thermodynamics; and Moss and Case's (1999) curriculum for teaching rational number. It is interesting that Ohlsson's example of a teaching intervention that embodies his own instructional recommendationsthat is, teaching physics in the context of an unfamiliar microworld (White, 1984; White \& Frederiksen, 1990) - is not particularly apt. Ohlsson (2009/this issue) claims "the success of the White et al. microworlds for motion was that they introduced the laws of motion in a gamelike situation removed far enough from everyday experience of moving objects so as not to evoke interfering intuitions" (p. 36), but how could microworlds populated with moving objects not evoke preexisting mechanical intuitions? Motion is motion, regardless of whether the moving object is a rocket or a cursor.

My point is not that White and her colleagues should have used a different instructional strategy but that withindomain approaches to conceptual change can be effective. Moreover, I do not doubt that across-domain approaches can be effective-Slotta and Chi (2006) have shown that they are-but I do happen to doubt that across-domain approaches are generally more effective than within-domain approaches. The problem with across-domain approaches is that, in addition to teaching students the target theory (e.g., evolution 
by natural selection) in another domain of knowledge (e.g., commercial market), instructors must also demonstrate how and why the target theory is applicable to the target domain itself (e.g., biological adaptation). If every initial illustration of the target theory involves entities and events far removed from the target domain, then students are likely to begin the process of competitive evaluation with little confidence that the target theory can actually subsume the target domain. Thus, from the instructor's point of view, the effort needed to guide students through the process of resubsumption may be greater than the effort needed to shield them from their own misconceptions. Even Ohlsson (2009/this issue) admits that "abstraction and transfer are not strong cards of human cognition, so what is won in lack of resistance from prior intuitions might be lost in the translation" (p. 37).

Despite my reluctance to endorse resubsumption as a way of introducing new forms of knowledge, I think resubsumption might prove quite effective at promoting the consolidation of that knowledge, once firmly grounded in the target domain. For instance, an instructor charged with the task of teaching evolution by natural selection could introduce this theory in the domain of biology and then lead students through an analogy between biological evolution and cultural evolution as a way of helping them differentiate the causal properties of natural selection (e.g., "alters gene frequencies," "operates over populations") from the noncausal ones (e.g., "is slow," "is nondeterministic"). An instructional strategy of this nature promises to reap the benefits of resubsumption (i.e., belief reinterpretation and concept reanalysis) without incurring the costs of knowledge transfer across domains. It is also more consistent with the view put forth here that resubsumption serves to complete, rather than initiate, conceptual change. Empirically pitting this strategy against a "resubsumption first" strategy might thus shed light on whether, and how, resubsumption is actually involved in knowledge restructuring.

\section{REFERENCES}

Au, T. K. (1994). Developing an intuitive understanding of substance kinds. Cognitive Psychology, 27, 71-111.

Au, T. K. F., Chan, C. K. K., Chan, T. K., Cheung, M. W. L., Ho, J. Y. S., \& Ip, G. W. M. (2008). Folkbiology meets microbiology: A study of conceptual and behavioral change. Cognitive Psychology, 57, 1-19.

Bartsch, K., \& Wellman, H. M. (1995). Children talk about the mind. Oxford, UK: Oxford University Press.

Carey, S. (1985). Conceptual change in childhood. Cambridge, MA: MIT Press.

Carey, S. (1991). Knowledge acquisition: enrichment or conceptual change? In S. Carey \& R. Gelman (Eds.), The epigenesis of mind: Essays in biology and cognition (pp. 257-291). Hillsdale, NJ: Erlbaum.

Carey, S. (1999). Sources of conceptual change. In E. K. Scholnick, K. Nelson, S. A. Gelman, \& P. Miller (Eds.), Conceptual development: Piaget's legacy (pp. 293-326). Hillsdale, NJ: Erlbaum.
Carey, S. (2000). Science education as conceptual change. Journal of Applied Developmental Psychology, 21, 13-19.

Chi, M. T. H. (2005). Commonsense conceptions of emergent processes: Why some misconceptions are robust. The Journal of the Learning Sciences, 14, 161-199.

Chi, M. T. H., \& Hausmann, R. G. M. (2003). Do radical discoveries require ontological shifts? In L. V. Shavinina (Ed.), International handbook on innovation (pp. 430-444). Oxford, UK: Elsevier Science.

Clement, J. (1982). Students' preconceptions in introductory mechanics. American Journal of Physics, 50(1), 66-70.

Demastes, S. S., Settlage, J., \& Good, R. (1995). Students' conceptions of natural selection and its role in evolution: Cases of replication and comparison. Journal of Research in Science Teaching, 32, 535-550.

Evans, E. M. (2008). Conceptual change and evolutionary biology: A developmental analysis. In S. Vosniadou (Ed.), Handbook of research on conceptual change (pp. 263-294). New York: Taylor \& Francis.

Fodor, J. A. (1981). The present status of the innateness controversy. In J. Fodor (Ed.), Representations: Philosophical essays on the foundations of cognitive science (pp. 257-316). Cambridge, MA: MIT Press.

Gentner, D., \& Wolff, P. (2000). Metaphor and knowledge change. In E. Dietrich \& A. Markman (Eds.), Cognitive dynamics: Conceptual change in humans and machines (pp. 295-342). Mahwah, NJ: Erlbaum.

Gopnik, A., Glymour, C., Sobel, D., Schulz, L. E., Kushnir, T., \& Danks, D. (2004). A theory of causal learning in children: Causal maps and Bayes nets. Psychological Review, 111, 1-31.

Gopnik, A., Sobel, D. M., Schulz, L. E., \& Glymour, C. (2001). Causal learning mechanisms in very young children: Two, three, and four-yearolds infer causal relations from patterns of variation and covariation. Developmental Psychology, 37, 620-629.

Gopnik, A., \& Tenenbaum, J. B. (2007). Bayesian networks, Bayesian learning, and cognitive development. Developmental Science, 10, 281-287.

Gruber, H. (1974). Darwin on man: A psychological study of scientific creativity. London: Wildwood House.

Halloun, I. A., \& Hestenes, D. (1985). Commonsense concepts about motion. American Journal of Physics, 53, 1056-1065.

Harris, P. L., \& Koenig, M. (2006). Trust in testimony: How children learn about science and religion. Child Development, 77, 505-524.

Hayes, B. K., Goodhew, A., Heit, E., \& Gillan, J. (2003). The role of diverse instruction in conceptual change. Journal of Experimental Child Psychology, 86, 253-276.

Jefferys, W., \& Berger, J. (1992). Ockham's razor and Bayesian analysis. American Scientist, 80, 64-72.

Kitcher, P. (1993). The advancement of science. New York: Oxford University Press.

Klahr, D., \& Dunbar, K. (1988). Dual space search during scientific reasoning. Cognitive Science, 12, 1-55.

Klahr, D., Fay, A. L., \& Dunbar, K. (1993). Heuristics for scientific experimentation: A developmental study. Cognitive Psychology, 25, 111-146.

Koslowski, B. (1996). Theory and evidence: The development of scientific reasoning. Cambridge, MA: MIT Press.

Kuhn, D., Amsel, E., \& O'Laughlin, M. (1988). The development of scientific thinking skills. Orlando, FL: Academic Press.

Kuhn, T. S. (1962). The structure of scientific revolutions. Chicago: University of Chicago Press.

Kuhn, T. S. (1977). The essential tension. Chicago: University of Chicago Press.

Kushnir, T., \& Gopnik, A. (2005). Children infer causal strength from probabilities and interventions. Psychological Science, 16, 678-683.

Le Corre, M., Van de Walle, G., Brannon, E. M., \& Carey, S. (2006). Re-visiting the competence/performance debate in the acquisition of the counting principles. Cognitive Psychology, 52, 130-169.

Mayr, E. (1982). The growth of biological thought: Diversity, evolution, and inheritance. Cambridge, MA: Harvard University Press.

Mayr, E. (2001). What evolution is. New York: Basic Books.

McCloskey, M. (1983). Naïve theories of motion. In D. Gentner \& A. Stevens (Eds.), Mental models (pp. 299-324). Hillsdale, NJ: Erlbaum. 
McCloskey, M., Caramazza, A., \& Green, B. (1980). Curvilinear motion in the absence of external forces: Naïve beliefs about the motion of objects. Science, 210, 1139-1141.

Millman, A. B., \& Smith, C. L. (1997). Darwin's use of analogical reasoning in theory construction. Metaphor and Symbol, 12, 159-187.

Moss, J., \& Case, R. (1999). Developing children's understanding of the rational numbers: A new model and an experimental curriculum. Journal for Research in Science Education, 30(2), 122-147.

Nakhleh, M. B., Samarapungavan, A., \& Saglam, Y. (2005). Middle school students' beliefs about matter. Journal of Research in Science Teaching, 42, 581-612.

Nersessian, N. J. (1992). How do scientists think? Capturing the dynamics of conceptual change in science. In R. N. Giere (Ed.), Cognitive models of science (pp. 3-45). Minneapolis: University of Minnesota Press.

Nersessian, N. J. (2008). Mental modeling in conceptual change. In S. Vosniadou (Ed.), Handbook of research on conceptual change (pp. 391-416). New York: Taylor \& Francis Group.

Ohlsson, S. (2009/this issue). Resubsumption: A possible mechanism for conceptual change and belief revision. Educational Psychologist, 44, 20 40.

Piaget, J., \& Inhelder, B. (1974). The child's construction of quantities. London: Routledge \& Kegan Paul.

Popper, K. (1956). The logic of scientific discovery. New York: Harper \& Row.

Posner, G. J., Strike, K. A., Hewson, P. W., \& Gertzog, W. A. (1982). Accommodation of a scientific conception: Toward a theory of conceptual change. Science Education, 66, 211-227.

Rakoczy, H., Warneken, F., \& Tomasello, M. (2007). "This way!”, "No! That way!"-3-year-olds know that two people can have mutually incompatible desires. Cognitive Development, 22, 47-68.

Reichenbach, H. (1938). Experience and prediction. Chicago: University of Chicago Press.

Schulz, L. E., \& Bonawitz, E. B. (2007). Serious fun: Preschoolers engage in more exploratory play when evidence is confounded. Developmental Psychology, 43, 1045-1050.

Schulz, L. E., \& Gopnik, A. (2004). Causal learning across domains. Developmental Psychology, 40, 162-176.

Shtulman, A. (2006). Qualitative differences between naïve and scientific theories of evolution. Cognitive Psychology, 52, 170-194.

Shtulman, A., \& Calabi, P. (2008). Learning, understanding, and acceptance: The case of evolution. Proceedings of the 30th Annual Conference of the Cognitive Science Society (pp. 235-240). New York: Routledge.

Shtulman, A., \& Schulz, L. E. (2008). The relation between essentialist beliefs and evolutionary reasoning. Cognitive Science, 32, 1049-1062.

Shultz, T. R. (2007). The Bayesian revolution approaches psychological development. Developmental Science, 10, 357-364.

Slaughter, V., \& Lyons, M. (2003). Learning about life and death in early childhood. Cognitive Psychology, 43, 1-30.

Slotta, J. D., \& Chi, M. T. H. (2006). Helping students understand challenging topics in science through ontology training. Cognition and Instruction, 24, 261-289.
Smith, C., Carey, S., \& Wiser, M. (1985). On differentiation: A case study of the development of the concepts of size, weight, and density. Cognition, $21,177-237$

Smith, C., Maclin, D., Grosslight, L., \& Davis, H. (1997). Teaching for understanding: A study of students' preinstruction theories of matter and a comparison of the effectiveness of two approaches to teaching about matter and density. Cognition and Instruction, 15, 317-393.

Sobel, D. M., \& Kirkham, N. Z. (2006). Blickets and babies: The development of causal reasoning in toddlers and infants. Developmental Psychology, 42, 1103-1115.

Sobel, D. M., Tenenbaum, J. B., \& Gopnik, A. (2004). Children's causal inferences from indirect evidence: Backwards blocking and Bayesian reasoning in preschoolers. Cognitive Science, 28, 303-333.

Solomon, G. E. A., Johnson, S. C., Zaitchik, D., \& Carey, S. (1996). Like father, like son: Young children's understanding of how and why offspring resemble their parents. Child Development, 67, 151-171.

Steyvers, M., Tenenbaum, J. B., Wagenmakers, E. J., \& Blum, B. (2003). Inferring causal networks from observations and interventions. Cognitive Science, 27, 453-489.

Tenenbaum, J. B., Griffiths, T. L., \& Kemp, C. (2006). Theory-based Bayesian models of inductive learning and reasoning. Trends in Cognitive Sciences, 10, 309-318.

Tenenbaum, J. B., Griffiths, T. L., \& Niyogi, S. (2007). Intuitive theories as grammars for causal inference. In A. Gopnik \& L. Schulz (Eds.), Causal learning: Psychology, philosophy, and computation (pp. 301-322). New York: Oxford University Press.

Thagard, P. (1992). Conceptual revolutions. Princeton, NJ: Princeton University Press.

Vosniadou, S. (1994). Capturing and modeling the process of conceptual change. Learning and Instruction, 4, 45-69.

Vosniadou, S., \& Brewer, W. F. (1987). Theories of knowledge restructuring in development. Review of Educational Research, 57, 51-67.

Vosniadou, S., \& Brewer, W. F. (1992). Mental models of the earth: A study of conceptual change in childhood. Cognitive Psychology, 24, 535-585.

Vosniadou, S., Ioannides, C., Dimitrakopoulou, A., \& Papademetriou, E. (2001). Designing learning environments to promote conceptual change in science. Learning and Instruction, 11, 381-419.

White, B. (1984). Designing computer activities to help physics students understand Newton's laws of motion. Cognition and Instruction, 1, 69108.

White, B., \& Frederiksen, J. (1990). Causal model progressions as a foundation for intelligent learning environments. Artificial Intelligence, 42, 99-157.

Wiser, M., \& Amin, T. (2001). Is heat hot? Inducing conceptual change by integrating everyday and scientific perspectives on thermal phenomena. Learning and Instruction, 11, 331-355.

Wynn, K. (1990). Children's understanding of counting. Cognition, 36, 155193.

Zietsman, A., \& Clement, J. (1997). The role of extreme case reasoning in instruction for conceptual change. Journal of the Learning Sciences, 6, 61-89. 